\title{
Aa. Vv., «Cahiers Octave Mirbeau» n. 17
}

\section{Ida Merello}

\section{(2) OpenEdition}

\section{Journals}

\section{Edizione digitale}

URL: http://journals.openedition.org/studifrancesi/6063

DOI: 10.4000/studifrancesi.6063

ISSN: 2421-5856

\section{Editore}

Rosenberg \& Sellier

\section{Edizione cartacea}

Data di pubblicazione: 1 mai 2011

Paginazione: 204

ISSN: 0039-2944

\section{Notizia bibliografica digitale}

Ida Merello, «Aa. Vv., «Cahiers Octave Mirbeau» n. 17», Studi Francesi [Online], 163 (LV | I) | 2011, online dal 30 novembre 2015, consultato il 10 janvier 2021. URL: http://journals.openedition.org/ studifrancesi/6063 ; DOI: https://doi.org/10.4000/studifrancesi.6063

Questo documento è stato generato automaticamente il 10 janvier 2021.

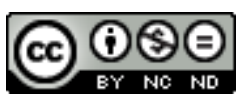

Studi Francesi è distribuita con Licenza Creative Commons Attribuzione - Non commerciale - Non opere derivate 4.0 Internazionale. 


\section{Aa. Vv., «Cahiers Octave Mirbeau» n. 17}

Ida Merello

NOTIZIA

«Cahiers Octave Mirbeau» n. 17, 2010, pp. 376.

$1 \quad$ La Société Octave Mirbeau diretta da Pierre MICHEL continua con le sue pubblicazioni nel rispetto rigoroso dei tempi e offrendo sempre abbondanza di materiali. In apertura lo stesso Pierre MICHEL indaga su una commedia sconosciuta di Mirbeau, La Gomme, che «Le Gaulois» indica come scritta sotto il nome di Gardéniac. Per l'A. la sola novella firmata da Gardéniac e in grado di essere trasposta in quattro atti è Dette d'honneur, del 26 marzo 1882; mentre la sola pièce che ha per titolo La Gomme esce nel 1889 pubblicata da Félicien Champsaur con tutt'altro soggetto. Ma un'analisi stilistica dettagliata lascia supporre all'A. che la scrittura sia quella di Mirbeau. Dorothée PAUVERT-RAIMBAULT incoraggia la tesi di pierre MICHEL - pur immaginando una scrittura a più mani piuttosto che l'impiego di Mirbeau come nègre - e ricorda come Champsaur fosse soprattutto abile nella mise en page dove utilizzava le competenze degli illustratori. olga AMARIE (O.M. et Juliette Adam: le Calvaire censuré, pp. 40-67) ripercorre il faticoso rapporto tra Mirbeau e la direttrice di «La Nouvelle Revue», Juliette Adam, femminista e patriota, i cui atti censori non intervenivano sulle scelte linguistiche, anche forti, ma su tutto ciò che le sembrava lesivo dell'immagine della Francia o di esaltazione tedesca, fosse anche la musica di Wagner. L'A. ricorda però come proprio la censura esercitata su Le Calvaire sia stata all'origine del suo successo. Yannick LEMARIÉ passa in rassegna le immagini della morte nell'opera di Mirbeau, in un clima generale di derelizione. Se in Le Calvaire la tomba conosce diversi avatar (tra cui l'appartamento stesso del rapporto di coppia del protagonista), le figure tradizionali della morte sono ovunque presenti, sia allegoriche, come la Falciatrice, che simboliche, come gli animali psicopompi, o fantastiche, come i fantasmi; l'A. nota anche una particolare insistenza dell'immagine mitica della soglia. 
Annie RIZK (De Mirbeau à Genet: les bonnes et le crime en littérature, pp. 68-86) riflette sulla perdita d'identità personale che il ruolo di domestica comporta e la sua propensione al crimine attraverso una lettura del Journal d'une femme de chambre confrontato con Les Bonnes di Genet. sandour KALAI (Les récits d'une société criminelle, pp. 77-87) elabora invece un elenco ragionato dei diversi tipi di crimine nei 21 jours d'un neurasthénique, riconducendo il racconto di delitti al gusto generale della Belle Époque, e distinguendo i crimini dovuti a mancanze deontologiche, agli errori e gli abusi della giustizia, alla corruzione politica ed economica, con attenzione alle diverse tecniche di narrazione. Fernando CIPRIANI (Cruauté, monstruosité et folie dans les contes de Mirbeau et de Villiers, pp. 88-108) paragona la crudeltà nei racconti dei due autori, che si conoscevano e si stimavano. Angela DI BENEDETTO (La parole à l'accusé: dire le mal dans les Contes cruels, pp. 109-121) mostra come i racconti di Mirbeau si modellino su fatti di cronaca nera con l'intenzione di scandalizzare e di colpire, e come l'emozione immediata sia cercata attraverso la finzione di un racconto orale attribuito a un narratore omodiegetico. Fabienne MASSANI-LEVAHAR (Quelques figures animalières dans l'œuvre d'Octave Mirbeau, pp.122-128) ci informa sul bestiario di Mirbeau e le sue valenze allusive. claude HERZFELD (Mirbeau et Léon Bloy, convergences, pp.130-145) individua il punto di convergenza di due scrittori ideologicamente opposti nello spirito individualista e in una certa analogia retorica, con similitudini nell'uso delle figure, dei neologismi e dei termini rari. céline BEAUDET (Zola et Mirbeau face à l'anarchie, pp. 147-155) sintetizza in maniera efficace i rapporti dei due scrittori con gli ambienti anarchici, e rintraccia l'influenza su questi ultimi di Le Travail di Zola e Les Mauvais Bergers di Mirbeau, mostrando altresì il diverso atteggiamento delle due opere e dei rispettivi autori nei confronti della classe operaia. christian Limousin (En visitant les expos avec Mirbeau, pp. 156-171) ricorda come la critica d'arte di Mirbeau costituisca una battaglia in nome del vero e del sano contro la retorica dell'ufficialità, e ripercorre i suoi odi e i suoi amori: la battaglia per Corot contro Cabanel, l'entusiasmo - di breve durata-per Gauguin, la stima costante per Rodin, l'occhio attento all'evoluzione della pittura di Monet, lo scarso apprezzamento per Guillaumin ecc. Il volume è corredato di una consistente sezione di documenti e una ricca sezione bibliografica. 